\title{
Research on Application of the Competition Method to Improve Learning Effects of Tennis Courses in the Universities
}

\author{
Xin Wei \\ Jilin Agricultural University, Changchun 130118, Jilin, China \\ 1005488505@qq.com
}

Keywords: The competition method; Tennis; Learning effects; Interest

\begin{abstract}
The competition method is an effective teaching method to practice by setting competition rules in the process of $\mathrm{PE}$ teaching. It can be regarded as a method to practice according to competition rules and competition forms under the approximate and simulated or real and strict conditions. It is also a method that is used widely in PE courses and the effects of this method are much better. The learning effects of students refer to learning interest of students and skills of students in this paper. In order to find a way to help students who are taking special tennis courses to improve interest and strengthen skills during tennis practicing courses, the method of literature, the method of questionnaires, the method of data statistics, the method of interviewing and the method of experiments are used in this paper. The twenty-four experimental participants whose major are PE education and social PE come from three different PE colleges. The competition method was used in teaching during the process of experiment to test whether the competition method can really improve learning effects of students who take special tennis courses or not. The result shows that the competition method is obviously good for students to arouse interest of learning tennis. The result also shows that the competition method may not be effective to improve learning skills of students within the short time of teaching tennis by the competition method.
\end{abstract}

\section{Introduction}

Current Situation of Offering Tennis Courses in the Universities. Tennis, as one of preferable sports among people, has a more than one-hundred-year history. However, tennis has not been popularized in China. The number of people who can play tennis is still limited, so the mass base is still weak [1]. With the improvement of living standard and cultural standard among people in recent years, the number of people who play tennis in the universities and all classes of the society is increasing year by year [2]. Some universities have offered tennis courses in succession and established mass organizations, such as the tennis amateur clubs. Tennis has gradually become the most favorite sport of university students [3]. The proportion of university students who take tennis as an optional course and amateur training has been very large. However, in terms of current teaching and training situation of tennis in the universities, the dull skill training that separates from competitions occupies the most of tennis training time, even all the tennis training time. Pure skill training that is repeatedly done gradually frittered away the competitive instinct and desires of the young. They even do not know how to compete with others [4]. They will feel that they just finish tennis training mechanically without thinking, diligence and proper tension. As a result, learning interest of students will become lower and lower so that tennis skills will not be also improved.

Main Problems Existing in Tennis Sport of University Students. The first problem is about facilities in tennis courts. Facilities in tennis courts are one of important guarantees to play tennis. With the accelerating pace of enrollment expansion of universities, teaching buildings, dormitory buildings and other basic facilities will be built so that the available floor space will decrease on campus [5, 6]. It is more difficult to build tennis courts, which need much investing money and floor space. Offering tennis courses in the universities and arousing interest of tennis exercise in their spare time has been restricted badly [7].

The second problem is about levels of tennis teachers. The situation of teachers or instructors who 
undertake tennis teaching and training in the universities is not good enough at present. Few teachers majoring tennis graduated from PE universities. Most of teachers get tennis skills by short-time training or self-learning so that teachers can not guarantee the teaching quality. It is not conducive for students to cultivating their interest in tennis and develop exercising habits [8].

The third problem is about textbooks for tennis. In terms of structure of textbooks, textbooks can not guide students to learn about tennis deeply and fully and can not cultivate students' learning ability of tennis. Students can only know what right skills are. But they do not know how to learn and master the right skills and improve tennis skills [9].

The fourth problem is about teaching content and teaching methods of tennis. There is nearly no theory course at tennis courses in the universities at present. The teaching content of optional courses is mainly about the forehand and backhand strokes or the overhand serve. There is no teaching competition. It is difficult to make students master the basic skills and tactics of tennis, competition rules and judging methods within regulated courses [10].

Motivations of Playing Tennis among University Students. The first one is that playing tennis can help them to build body and keep fit. According to a survey, $81.3 \%$ of students thought that playing tennis is good for health and playing tennis can make their spare entertainment life more colorful. Playing tennis has become a necessary part in their life. Playing tennis has been an important component in their spiritual and cultural life. They insist to take tennis as a main exercise so that they can possess a stronger body.

The second one is that playing tennis can help them to cultivate consciousness of modern competitive ability. University students, as amateur tennis competitors, usually have clear aims during competitions. Every participant will be involved in competitions and self-expression to the greatest degree. Taking part in competitions is good for people to cultivate competitive spirits and struggling spirits. Tennis competitions are good for people to cultivate their modern ways of thinking. Players need to judge the varying situation of competitions and take countermeasures bravely. We can draw a conclusion that tennis competitions play a positive role in cultivating expecting ability and responding ability.

The third one is that playing tennis can help them to cultivate communicating ability by tennis. Common interest and hobby can reassemble people who have different characteristics. They can make friends by competitions and tennis. Being in the temporary team, people can display themselves and self-value, exchange thinking, show feelings, remove gaps and communicate mutually to develop friendship. As a result, tennis has been an important channel for university students to make friends and expand their horizon.

All in all, according to the situation of offering tennis courses in the universities, using the competition method at tennis courses has much more reality meaning and long-term meaning from the perspective of main problems existing in university students' tennis sports and motivations of playing tennis.

\section{Results and Discussion}

What the Competition Method Is. The competition is an effective teaching method to practice by setting competition rules in the process of PE teaching. It can be regarded as a method to practice according to competition rules and competition forms under the approximate and simulated or real and strict conditions. It is also a method that is used widely in PE courses and the effects of this method are much better.

Teaching Principles by Using the Competition Method. The first principle is that matches can be held after students have mastered certain skills. As coaches, they must combine matches with teaching content closely before matches. Otherwise, it is not meaningful to use matches in the teaching process. When students can not master actions well and apply actions smoothly, coaches should not hold matches in a hurry. At the phase of mastering and improving actions roughly, matches relating to action quality should not be held because it is easy to break the formation of correct actions. At the same time, injury accidents will happen easily. 
The second principle is that teachers should use the competition method by grasping good opportunities. Generally speaking, students can apply actions appropriately after they have mastered skills and actions. If students mastered skills and actions well, they would perform their grades, take part in matches actively and strive for victory hardly so that matches can play a positive role. On the contrary, students have not mastered some skills and actions, holding matches will make students lack courage and confidence. If some students did not win, they will lose interest and confidence of playing tennis. Meanwhile, skills and actions that are not still enhanced will be broken so that training can not achieve the expected effects.

The third principle is that when teachers use the competition method, they need to adjust and control physical activities of courses. Organizational work should be finished well because matches will be introduced into courses and the number of all kinds of matches will increase. According to age, gender, physical condition and sports foundation of students, physical activities should be arranged reasonably. Students need to perform their all kinds of abilities to the greatest degree for victory during matches. When students are tired and take part in matches reluctantly, the results will not be good. Students may get overloaded exercises so that injury accidents may happen.

The fourth principle is that teachers can use the competition method by combining teaching content closely, finding and correcting problems. During the matches, students should take part in matches actively and seriously, obey matches rules strictly and perform motivating spirits and innovative spirits of students fully so that the atmosphere of matches can be more active. However, it needs to be clarified that although the matches can be a method in the teaching process, too many matches should not be arranged during a training course. The training courses should combine with teaching content closely. Meanwhile, the courses need to combine with matches and conclusions, and then students can find shortcomings and weak skills loop so that they can correct and practice their basic skills timely.

The fifth principle is that the ideological education should be run through the whole match. The principle of running ideological education should make students have clear match objectives so that students can perform actively during practice. Students should be educated to respect referees, obey rules and respect the opposite side. They should not take deception and opportunism, ignore rules and principles and chase victory purely. Teachers should cultivate students with the discipline, the braveness, the tenacity, solidarity and collaboration and other qualities. Students should be people who conquered but are not proud.

Significance of Teaching by the Competition Method. The first one is that teaching by the competition method is conducive to improving learning interest of students. In terms of the process of mastering skills, the repeating practice needs to be done to form a sports skill and master it. If students lack the purposes of practicing the basic skills and practicing process lack necessary transformation conditions, the repeating practice will become dull and boring. As a result, students' attention has been scattered and their actions are careless. The situation of matches is varying. Students need to deal with different situations by applying learned skills according to requirements and content of matches. The varied stimulation of matches and application of skills can arouse learning interest of students effectively.

The second one is that teaching by the competition method is conducive to pushing students to learn basic skills actively. Students who take matches should have some basic skills. A successful hitting can bring an exciting experience for students. In order to gain more happiness and experience more fun during matches, students will practice basic skills unconsciously and apply learned skills into matches. The reasonable application of the competition method provides conditions that can stimulate people and arouse strong interest. The competition method can push students to master action essentials quickly within the short time and consolidate the quality of actions.

The third one is that teaching by the competition method is conducive to improving the psychological quality. Theories of sport training point out that the physical ability, skills, tactical ability and sports intelligence of athletes can be shown out only with the participation and cooperation of psychological ability in the process of training and matches of competitive sports. During special tennis courses, teaching by the competition method can constantly build up and 
improve their adaptability and ability of controlling their emotions even though they lack opportunities of taking ordinary matches.

The fourth one is that teaching by the competition method is conducive to pushing students to learn and understand basic tactical coordination. During the doubles matches, there is an unexpressed joy that students can finish a attack-defense and get success by coordination. When students practice tactics, positions and the shot time are both basically fixed. Only in the matches, can students deeply experience and master the importance of positions and the shot time. At the same time, they can understand that how to apply the learned tactics. Students can know the time of hitting smash, the time of hitting backspin and the time of hitting topspin by practicing, experiencing and mastering. This must not be only dependent on practices.

The fifth one is that teaching by the competition method is conducive to pushing students to master competition rules of tennis and judging rules. The practice shows that students can effectively master competition rules of tennis and judging rules only by competitions and judging internship combining with interpretation of theories and class discussions. Students can analyze different situations occurring in the matches so that they can understand and remember competition rules of tennis and judging rules better. If students recite rules mechanically, it is easy to forget and hard to see the effects.

The sixth one is that teaching by the competition method is conducive to cultivating good volitional quality of students. At the atmosphere of matches, personalized psychological characteristics and volitional quality of students are easy to be revealed. Teachers can also do positive education so that the teaching effects are more obvious by doing fewer things. Sometimes students do not obey the rules for victory. Some students will have negative emotions and yield difficulties when they are in the inferior position. Teachers should educate students flexibly so that the collectivism of students should be cultivated, such as the braveness, the tenacity, the coordination and unity. It is also helpful to strengthen the sense of responsibility, honor and friendship.

\section{Suggestions}

Accelerating the Pace of Building Tennis Courts and Facilities and Improving Utilization of Facilities in the Courts. Tennis courts and facilities are the basis of offering tennis courses and they are the fundamental guarantee to improve teaching quality of tennis courses. The universities should keep abreast of modern life, renewal concept and improve the environment of tennis training and tennis teaching. The universities also should implement scientific management and increase utilization of courts. Universities should reinforce management of tennis courts. Tennis courts in the universities should be taken full use in the morning, noon, afternoon, weekends and holidays with the premise of guaranteeing the usual teaching and training. The opening form should be flexible and variant. Universities can preserve courts and facilities by paying for teaching and courts fee so that the good cycling can be formed.

Construction of Tennis Teaching Team Should be based on Existing Teachers' Cultivation. Modern tennis sports and matches is not only battle between physical ability and skills, but also the battle between intelligence and consciousness. Strengthening training of existing teachers can solve current problems. Teachers should be required and offered more learning opportunities. Teachers should learn advanced skills, teaching methods and training methods at home and abroad so that they can satisfy students' needs towards tennis sports.

Clarifying Tennis Teaching Aims, Updating Tennis Teaching Methods and Diversifying Teaching Methods. Teachers have to transform the traditional ideas that teachers are the center of teaching. In fact, they play a leading role to provide service for students who are in the thematic position. Teachers should respect students' subjectivity of students fully and pay attention to learning methods of students. Teachers also should provide a relaxing and free environment and greatly make students try, practice and think by themselves. Students should be put into a learning process full of challenges and creativity so that their enthusiasm, interest and coordination can be aroused fully. 
Reinforcing the Development of Extracurricular Tennis Activities. It is so difficult to achieve tennis teaching aims by practice during around one hour, so the universities should create conditions to offer tennis extracurricular activities systematically. For example, universities can establish tennis clubs, hold tennis matches in or out of universities and so on so that students can be influenced by more tennis thinking and new concepts.

Improving All the Matches Institutes and Building a Good Tennis Matches Atmosphere. The beauty and vigor of sports come from matches. Matches can stimulate potentials of people and increase their sense of honor and achievement. As the units holding tennis matches, the universities should improve all the match institutes. At the same time, students can join to improve matches institutes and get the real joy of tennis. Some universities that have better conditions can organize students to take part in challenging matches in or out of universities so that students can learn tennis skills more actively.

\section{Conclusions}

This paper has searched and explored the competition method that can improve learning effects of tennis courses in the universities. The method of literature, the method of questionnaires, the method of data statistics, the method of interviewing and the method of experiments are used in this paper. The twenty-four experimental participants whose major are PE education and social PE come from three different PE colleges. The competition method was used in teaching during the process of experiment to test whether the competition method can really improve learning effects of students who take special tennis courses or not. The result shows that the competition method is obviously good for students to arouse interest of learning tennis. The result also shows that the competition method may not be effective to improve learning skills of students within the short time of teaching tennis by the competition method.

\section{References}

[1] S.Z.Ye: Journal of Fuqing Branch of Fujian Normal University, 2012, No.5, p.116. (In Chinese)

[2] W.D.Chen: Journal of Huaibei Professional and Technical College, Vol.12(2013), No.2, p.109. (In Chinese)

[3] P.X.Liu and T.T.Wu: Contemporary Sports Technology, Vol.4(2014), No.20, p.69. (In Chinese)

[4] H.Li: Journal of Chifeng University, Vol.29(2013), No.8, p.151. (In Chinese)

[5] S.J.Yang: Contemporary Sports Technology, Vol.5 (2015), No.12, p.80. (In Chinese)

[6] C.L.Wang: Industrial \& Science Tribune, Vol.14 (2015), No.9,p.181. (In Chinese)

[7] D.Xu: Journal of Kaifeng Institute of Education, Vol.33 (2013), No.4, p.116. (In Chinese)

[8] Z.Cao: Journal of Tianjin College of Commerce, Vol.2 (2014), No.3, p.52. (In Chinese)

[9] C.H.Liu: Journal of Changchun University of Science and Technology, Vol.7 (2012), No.5, p.231. (In Chinese)

[10] J.Hui: Journal of Changchun Education Institute, Vol.29 (2013), No.6, p.72. (In Chinese) 